\title{
Roles of STAT3 in leukemia (Review)
}

\author{
YIN SHI ${ }^{1,2^{*}}$, ZHEN ZHANG $^{2 *}$, XINTAO QU $^{3 *}$, XIAOXIAO ZHU ${ }^{2}$, LIN ZHAO $^{2}$, RAN WEI $^{2}$, QIANG GUO $^{2}$, \\ LINLIN SUN ${ }^{1,2}$, XUNQIANG YIN ${ }^{1,2}$, YUNHONG ZHANG ${ }^{1,2}$ and XIA LI ${ }^{2}$ \\ ${ }^{1}$ School of Medicine and Life Sciences, University of Jinan-Shandong Academy of Medical Sciences; \\ ${ }^{2}$ Laboratory for Molecular Immunology, Institute of Basic Medicine, Shandong Academy of Medical Sciences, \\ Jinan, Shandong 250062; ${ }^{3}$ Department of Bone and Joint Surgery Jinan Central Hospital \\ Affiliated to Shandong University, Jinan, Shandong 250013, P.R. China
}

Received February 8, 2018; Accepted April 24, 2018

DOI: $10.3892 /$ ijo.2018.4386

\begin{abstract}
Leukemia is a type of hematopoietic malignancy, and the incidence rate in the United States and European Union increases by an average of 0.6 to $0.7 \%$ annually. The incidence rate in China is approximately 5.17/100,000 individuals, and the mortality rate is $3.94 / 100,000$ individuals. Leukemia is the most common tumor affecting children and adults under 35 years of age, and is one of the major diseases leading to the death of adolescents. Signal transducer and activator of transcription 3 (STAT3) is a vital regulatory factor of signal transduction and transcriptional activation, and once activated, the phosphorylated form of STAT3 (p-STAT3) is transferred into the nucleus to regulate the transcription of target genes, and plays important roles in cell proliferation, differentiation, apoptosis and other physiological processes. An increasing number of studies have confirmed that the abnormal activation of STAT3 is involved in the development of tumors. In this review, the roles of STAT3 in the pathogenesis, diagnosis, treatment and prognosis of leukemia are discussed in the aspects of cell proliferation, differentiation and apoptosis, with the aim to further clarify the roles of STAT3 in leukemia, and shed light into possible novel targets and strategies for clinical diagnosis and treatment.
\end{abstract}

\section{Contents}

1. Introduction

2. The structure and regulation of the activity of STAT3

Correspondence to: Professor Xia Li, Laboratory for Molecular Immunology, Institute of Basic Medicine, Shandong Academy of Medical Sciences, 18877 Jingshi Road, Jinan, Shandong 250062, P.R. China

E-mail: 786735868@qq.com

*Contributed equally

Key words: signal transducer and activator of transcription 3, leukemia, pathogenesis, prognosis, STAT3-directed therapy
3. The role of STAT3 in the pathogenesis of leukemia

4. The roles of STAT3 in the diagnosis, treatment and prognosis of leukemia

5. Conclusion

\section{Introduction}

Leukemia, a common hematological malignancy, originates from clonal leukemia cells with uncontrolled proliferation, blocked cell apoptosis and differentiation disorders. Leukemia is characterized by accumulations of immature leukemic blasts in the bone marrow and hematopoietic tissues, infiltration of non-hematopoietic tissues and organs, and inhibition of normal hematopoietic function. The incidence of leukemia is increasing at an average rate of $0.7 \%$ annually in children and adolescents of the United States; in China the incidence of leukemia is approximately 5.17/100,000 individuals and the mortality rate is $3.94 / 100,000$ individuals, which severely endangers the lives of patients $(1,2)$. There are several types of leukemia, and these can be divided into four common types according to cell morphology and biochemical characteristics as follows: Acute lymphoblastic leukemia (ALL), chronic lymphoblastic leukemia (CLL), acute myeloid leukemia (AML) and chronic myeloid leukemia (CML) (3). The pathogenesis and clinical treatment for leukemias are 'hot' and difficult research directions in the field of cancer. STAT proteins (STATs) belong to a family of transcription factors that are activated by polypeptide ligands, such as cytokines and growth factors. STATs comprise seven members: STAT1, STAT2, STAT3, STAT4, STAT5 (a/b) and STAT6 (4). STAT3 is a crucial member of the STAT family, which forms a dimer following activation, enters the nucleus, and regulates the transcription of diverse target genes $(5,6)$. Since it is closely associated with cell proliferation, differentiation and apoptosis, its abnormal expression and activity are involved in the development of certain diseases, such as hyper-IgE syndrome and developmental abnormalities (7). An increasing number of studies have found that STAT3 abnormal expression and activation are accompanied by leukemia development, which indicates the potential role of STAT3 in the pathogenesis of leukemia (8-11). The present review focuses on the roles of STAT3 in the pathogenesis, diagnosis, treatment and prognosis of different types of leukemia. 


\section{The structure and regulation of the activity of STAT3}

The structure of STAT3. The STAT3 encoding gene is located on the human genome chromosome 17 (17q21.1) and the protein contains six classical functional segments of the STAT family: i) N-terminal domain (ND), which is able to stabilize the dimerized STAT3 and promote the formation of tetramers of two STAT3 dimers to make it more stable with DNA (12); ii) coiled-coil domain (CCD), which mediates STAT3 direct binding to the receptor and facilitates STAT3 phosphorylation on 705-tyrosine site (Y705) (13); iii) DNA binding domain (DBD), which, by recognizing the $\gamma$-interferon activating sequence (GAS), will direct STAT3 to the promoters of target genes, and initiate transcriptional activation of the target genes (14); iv) the linker region, the function of which unknown at present; v) Src homology 2 (SH2) domain, the most conserved part of STAT3, which shares the same core sequence 'GTFLLRFSS' with the SH2 domain of tyrosine kinase Src, and the phosphorylation and subsequent dimerization of $\mathrm{SH} 2$ domain and plays a critical role in the process of signal transduction (15); vi) C-terminal transcriptional activation domain (TAD), in which there are several important tyrosines/serines located or near the region, and the phosphorylation of specific residues are important for STAT3 function. For example, Y705 is located between SH2 and TAD, which is crucial for STAT3 activation and dimerization, and the 727-serine site (S727) is located in TAD, which is thought to enhance the transcriptional activity of STAT3 (16-18) (Fig. 1A).

STAT3 has four isoforms: STAT3 $\alpha$, STAT3 $\beta$, STAT $3 \gamma$ and STAT3 8 . Among the structures of STAT3 isoforms, STAT3 $\alpha$ is the most common structure. It consists of the ND, CCD, DBD, Linker, SH2 and TAD domains, with a molecular weight of approximately $92 \mathrm{kDa}$, and is mainly associated with cell proliferation and transformation $(19,20)$ (Fig. 1A). STAT3 $\beta$ originates from the alternative splicing of the STAT3 gene transcript, which results in a 55 amino acid deletion at the $3^{\prime}$ end of the open reading frame of STAT3 $\alpha$ with a molecular weight of approximately $83 \mathrm{kDa}$; STAT3 $\beta$ lacks the C-terminal transactivation domain and $\mathrm{S} 727$, and acts as a dominant transcriptional inhibitory factor that is particularly crucial for granulocyte colony-stimulating factor (G-CSF)-mediated cell differentiation (21-23) (Fig. 1B). STAT3 $\gamma$, with molecular weight of $72 \mathrm{kDa}$, acts as a dominant negative form of STAT3 $\alpha$. It lacks the $\mathrm{C}$-terminal transactivating portion, and due to controlled proteolysis, the corresponding residues of S727 and Y705 of STAT3 $\alpha$ are absent in STAT3 $\gamma$, which retains the $\mathrm{SH} 2$ domain and can be recruited to tyrosine-phosphorylated receptor proteins through the $\mathrm{SH} 2$ domain (Fig. 1C). STAT $3 \gamma$ is predominantly activated in terminal differentiated neutrophils, and is involved in the regulation of cell proliferation $(19,24)$. STAT3 $\delta$, a putative isoform of STAT3 with a yet unknown structure, has been found to be expressed during the early stage of granulocytic differentiation (25).

The regulation of STAT3 activity. STAT3 can be activated through a number of mechanisms, including through the Janus kinase (JAK)/STAT3, Ras/mitogen-activated protein kinase (MAPK) and non-receptor tyrosine kinase signaling pathways $(26,27)$. STAT3 is negatively regulated by two types of regulating factors, including the suppressor of cytokine signaling (SOCS) and the protein inhibitor of activated STAT (PIAS), which regulate the active status of STAT3 through different mechanisms (28). These activation pathways and regulatory factors regulate STAT3 activity and function synergistically, and play essential roles in physiological and pathological processes (29-31) (Fig. 2). A description of these activation pathways and regulatory factors is provided as follows:

a) The JAK/STAT3 pathway. The Janus kinase (JAK) family consists of four non-receptor tyrosine kinases, JAK1, JAK2, JAK3 and tyrosine kinase 2 (TYK2), which not only phosphorylate the bound cytokine receptors, but also a number of signaling molecules, which contain specific $\mathrm{SH} 2$ domains (32). Different cytokine receptors on the cell membrane bind the corresponding ligands to form homologous or heterodimers, which drive the mutual phosphorylation of the JAKs in proximity and facilitate the activation of STAT3 (33-38) (Table I). Mechanistically, the activated JAKs will phosphorylate tyrosine residues on the receptor, which provides a 'docking site' with the surrounding amino acid sequence for STAT3 protein recruitment by SH2 domain. Subsequently, STAT3 protein is phosphorylated by JAKs predominantly at the Y705 site, leading to the activation and dimerization of STAT3, which will rapidly enter the nucleus, specifically bind to the GAS sequence (TTC/ANNNG/TAA) or the interferon-stimulated response element sequence (AGTTTCNNTTCNC/T), and initiate the activation and transcription of target genes $(13,39,40)$. In addition, the activity of STAT3 in the nucleus needs to be tightly controlled. For example, STAT3 activity can be 'shut down' by the dephosphorylation effects of tyrosine phosphatase in the nucleus, or by proteolytic enzyme degradation of STAT3 protein.

b) The Ras-MAPK activation pathway. The role of Ras signaling in STAT3 activation has been demonstrated by numerous studies, whereby the Ras-induced activation of MAPKs and the subsequent MAPK-mediated phosphorylation of STAT3 may be required for STAT3 activity (41). The MAPK family includes extracellular signal-regulated kinases (ERKs), c-Jun N-terminal kinase (JNK) and p38 MAPK (p38), which act as components in the Ras signaling pathway with serine/threonine protein kinase activity (27). STAT3 is one of the MAPK substrates, and the MAPK-mediated phosphorylation of STAT3 on S727 will lead to STAT3 dimerization, its entry into the nucleus, its binding to specific DNA sequences in the promoters of genes, and the initiation of the activation and transcription of target genes; when MAPK is blocked, the promoting effects of STAT3 on target gene transcription are significantly decreased (42).

c) Non-receptor tyrosine kinase signaling pathways. In addition to JAK/STAT3 and Ras/MAPK pathways, nonreceptor tyrosine kinases, such as activated Src kinase and Abelson leukemia protein (Abl) can also directly phosphorylate STAT3 protein independently of ligand-induced receptor pathways. The activation of non-receptor tyrosine kinase signaling pathways also causes the simultaneous activation of MAPK family members, including p38, ERK and JNK, which phosphorylate STAT3 on S727 in the C-terminal transactivation domain. Following entry into the nucleus, the activated STAT3 proteins bind to specific DNA-response elements in 
$\mathbf{A}$

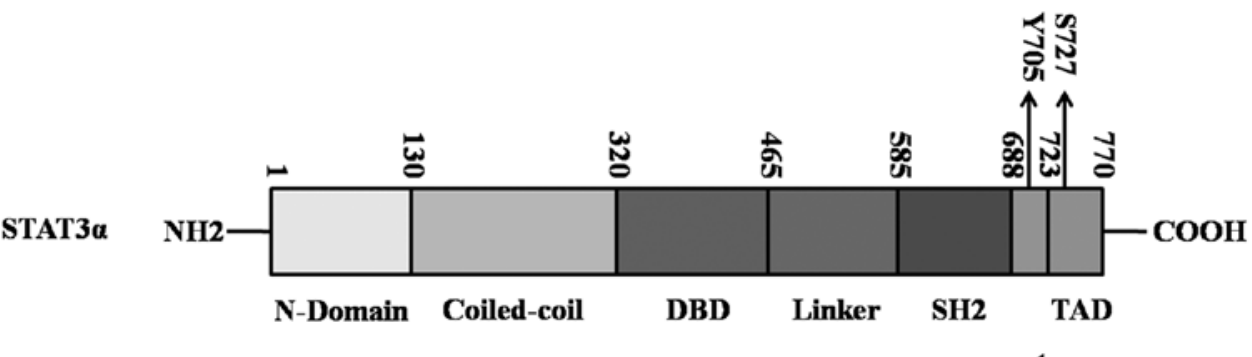

B

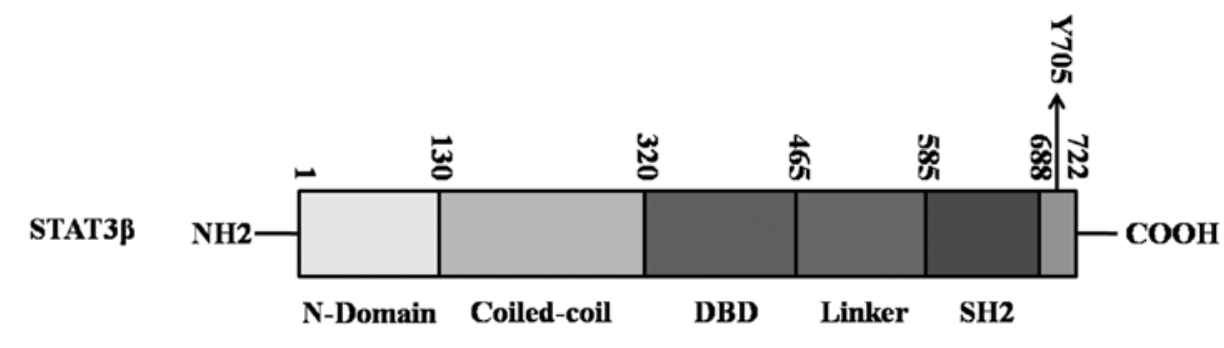

$\mathbf{C}$

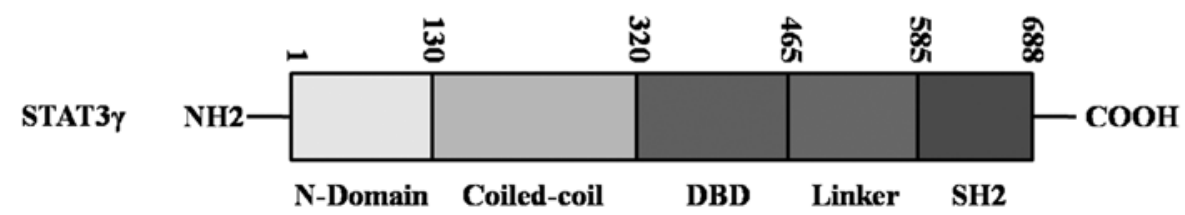

Figure 1. The structure of signal transducer and activator of transcription 3 (STAT3) isoforms. (A) STAT3 $\alpha$ is the full-length STAT3 protein, which consists of the N-terminal domain (ND), coiled-coil domain (CCD), DNA binding domain (DBD), Linker, Src homology 2 (SH2) and C-terminal transcriptional activation domain (TAD). (B) STAT3 $\beta$ is the truncated form of STAT3 $\alpha$, which lacks TAD and S727 compared to STAT3 $\alpha$. (C) STAT3 $\gamma$ is the truncated form of STAT3 $\alpha$, which lacks TAD, S727 and Y705.

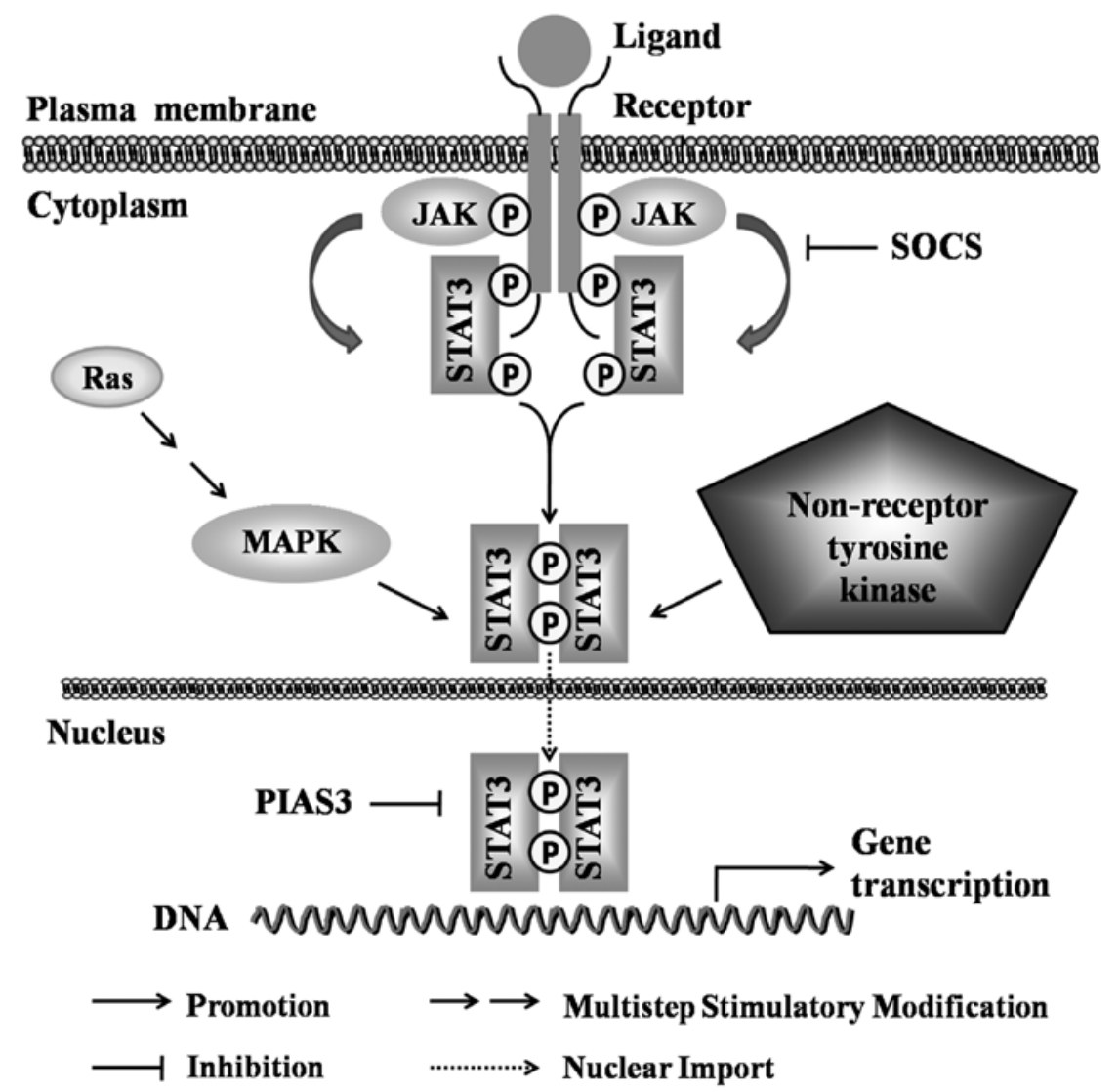

Figure 2. Regulation of STAT3 activity. STAT3 can be activated by the Janus kinase (JAK)/signal transducer and activator of transcription 3 (STAT3), Ras/mitogen-activated protein kinase (MAPK) and non-receptor tyrosine kinase signaling pathways. STAT3 is negatively regulated by the suppressor of cytokine signaling (SOCS) and protein inhibitor of activated STAT3 (PIAS3), which regulate the activity status of STAT3. 
Table I. Receptor-specific JAKs in the JAK/STAT3 pathway.

\begin{tabular}{lll}
\hline Receptors & \multicolumn{1}{c}{ JAKs } & (Refs.) \\
\hline Type II cytokine receptor & & $(33)$ \\
Interleukin-10 receptor & JAK1, TYK2 & \\
Receptor tyrosine kinase family & & $(34)$ \\
Epidermal growth factor receptor & JAK1, JAK2 & $(34)$ \\
Platelet-derived growth factor receptor & JAK1, JAK2, TYK2 & $(35)$ \\
Colony stimulating factor 1 receptor & JAK1, TYK2 & $(36)$ \\
Vascular endothelial growth factor receptor & JAK2 & \\
Receptors with gp130 domain & & $(33)$ \\
Interleukin-6 receptor & JAK1, JAK2, TYK2 \\
Interleukin-11 receptor & JAK1, JAK2, TYK2 & $(33)$ \\
Oncostatin M receptor & JAK1, JAK2, TYK2 \\
Leukemia inhibitory factor receptor & JAK1, JAK2, TYK2 & $(37)$ \\
Ciliary neurotrophic factor receptor & JAK1, JAK2 \\
Granulocyte colony-stimulating factor receptor & JAK1, JAK2, TYK2 & $(35)$ \\
Cardiotrophin-1 receptor & JAK1, JAK2 & $(38)$ \\
Receptors with $\gamma_{C}$ domain & & $(35)$ \\
Interleukin-2 receptor & & \\
Interleukin-7 receptor & JAK1, JAK3 & $(33)$ \\
Interleukin-9 receptor & JAK1, JAK3 & $(35)$ \\
Interleukin-15 receptor & JAK1, JAK3 & $(33)$ \\
\hline
\end{tabular}

JAK, Janus kinase; STAT3, signal transducer and activator of transcription 3; TYK, tyrosine kinase.

the promoters of genes and initiate the expression of unique genes through interactions with other transcriptional regulatory components $(27,41)$.

d) SOCS and PIAS regulatory pathways. STAT3 activity is negatively regulated by two major regulators, SOCS and PIAS (28). The SOCS family consists of eight members: SOCS1-7 and cytokine-inducible $\mathrm{SH} 2$-containing protein (CISH), and they negatively regulate the JAK/STAT3 signaling pathway via several mechanisms as follows: i) All SOCSs bind to receptor complexes or associated JAKs through their SH2 domains, recruit Elongin B/C heterodimers, Cullin5 and other components of a E3 ubiquitination complex, and lead to the degradation of receptors or associated JAKs via the proteasomal pathway; ii) SOCS1 and SOCS3 directly inhibit JAKs tyrosine activity via their kinase inhibitory region by binding to the JAK activation loop; iii) CISH, SOCS2 and SOCS3 can inhibit signaling transduction via their ability to bind to phosphotyrosine residues on receptors, thereby blocking the binding of other $\mathrm{SH} 2$-containing signaling molecules (JAKs/STAT3) to the receptors; iv) SOCS7 can prevent the nuclear translocation of p-STAT3, and inhibit the transcription of target genes $(43,44)$.

PIAS3 is currently known to be associated with STAT3 activity in the PIAS family, which affects STAT3 activation via several molecular mechanisms as follows: i) PIAS3 may inhibit transcription by blocking the DNA-binding activity of p-STAT3; ii) PIAS3 may suppress transcription by recruiting other co-regulators, such as histone deacetylases; iii) PIAS3 may regulate transcription by promoting the sumoylation of p-STAT3; iv) PIAS3 may suppress transcription by sequestering p-STAT3 to certain subnuclear structures where co-repressor complexes are enriched (45).

\section{The role of STAT3 in the pathogenesis of leukemia}

Leukemia cells and normal hematopoietic cells in the same bone marrow microenvironment have entirely different biological characteristics; normal hematopoietic cells, under the stimulation of cytokines, will continue to differentiate and mature; however, leukemia cells are characterized by differentiation failure and infinite proliferation. In normal cells, the activation of STAT3 is rapid and transient; however, in leukemia cells, abnormal STAT3 expression and activation always occur, which accelerate leukemia cell proliferation, block leukemia cell differentiation and inhibit leukemia cell apoptosis, leading to the occurrence and development of leukemia (46).

STAT3 and leukemia cell proliferation. In the process of leukemia cell proliferation, STAT3 can promote the proliferation of leukemia cells through JAK/STAT3, Ras/Raf/MAPK, $\mathrm{PI} 3 \mathrm{~K} / \mathrm{AKT} / \mathrm{mammalian}$ target of rapamycin (mTOR) and other signaling pathways. For example, G-CSF stimulates the activation of STAT3 $\alpha$ to promote the proliferation of AML cell lines (47), and protein kinase CK2 regulates the transcription of the Forkhead box $\mathrm{O} 3$ (FOXO3a) gene by activating STAT3 through JAK/STAT3 and PI3K/AKT/mTOR, and promotes the proliferation of leukemia stem cells (48). Moreover, STAT3 can also be activated via the JAK/STAT3 and Ras/Raf/MAPK 


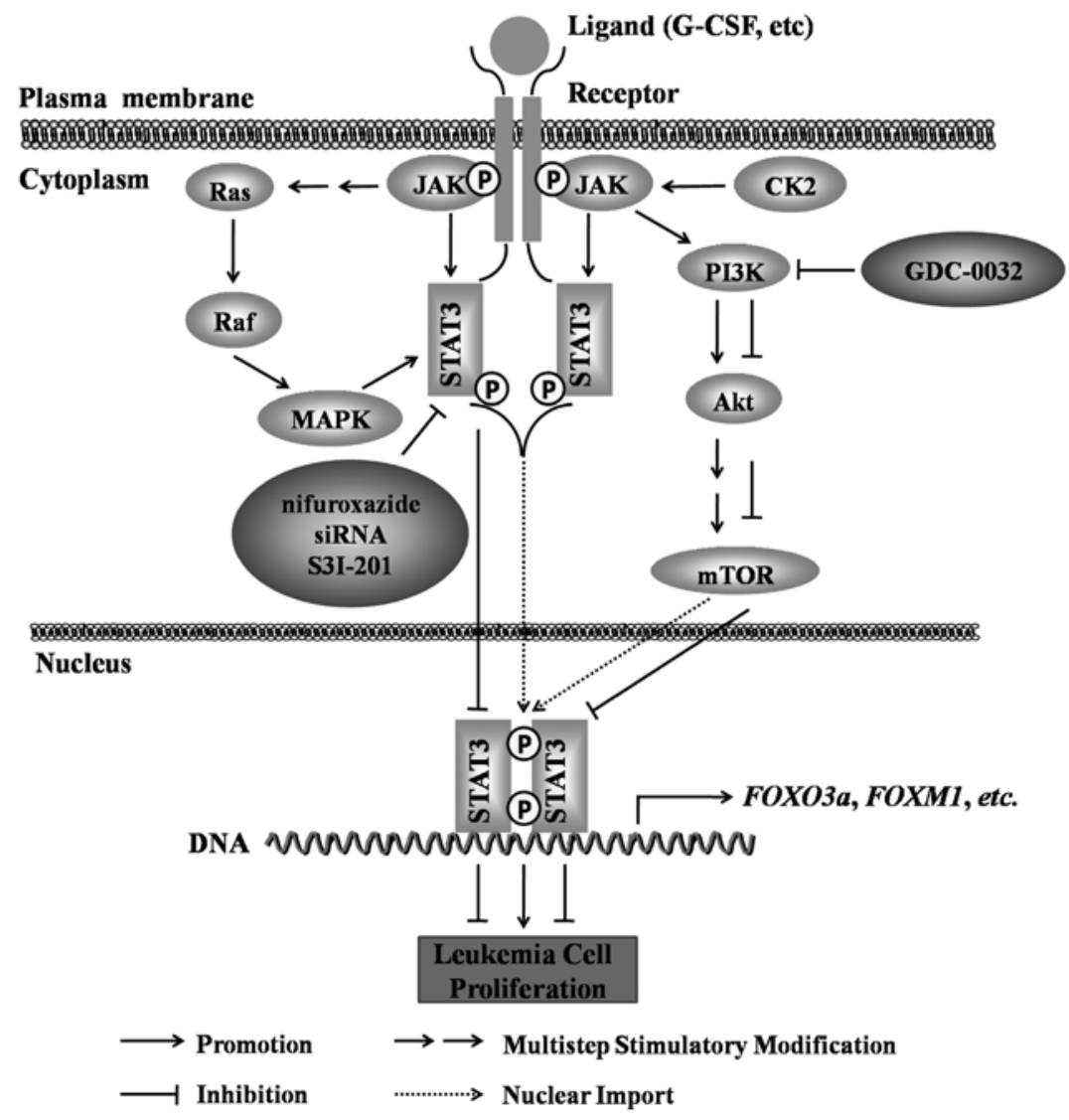

Figure 3. Roles of signal transducer and activator of transcription 3 (STAT3) in the proliferation of leukemia cells. STAT3 can promote the proliferation of leukemia cells through the Janus kinase (JAK)/STAT3, Ras/Raf/mitogen-activated protein kinase (MAPK), PI3K/AKT/mammalian target of rapamycin (mTOR) signaling pathways, and the inhibition of STAT3 activity can reduce the proliferation and survival of leukemia cells.

pathways, which initiates the transcription of the Forkhead box M1 (FOXM1) gene and promotes the proliferation of the CML cell line, K562 (49), wherease the inhibition of STAT3 activity can effectively reduce the proliferation and survival of leukemia cells (50-52). For example, the STAT3 inhibitor, nifuroxazide, and the PI3K inhibitor, GDC-0032, alone or in combination, have been shown to effectively reduce the proliferation of human ALL CCRF-CEM cells (50). In CD34 antigen-positive AML (AML CD34 ${ }^{+}$cells, the siRNA-mediated knockdown of STAT3 has been shown to significantly inhibit the growth and survival of AML CD34+ cells (51). In addition, it has been demonstrated that the combined use of the survivin gene inhibitor, YM155, with the STAT3 inhibitor, S3I-201, significantly inhibit the proliferation of YM155-tolerant human T lymphocytic leukemia MT-2 cells (52). These studies collectively suggest that STAT3 overexpression can promote leukemia cell proliferation and that the inhibition of STAT3 activity can reduce leukemia cell survival and proliferation (Fig. 3).

STAT3 and leukemia cell differentiation. Hematopoietic progenitor cells can be divided into myeloid and lymphoid progenitor cells. Myeloid progenitor cells have the potential to multi-differentiate into myeloid cells (erythrocytosis, granulocytosis, thrombocytosis, etc.), while lymphoid progenitor cells have the potential to differentiate into lymphatic subfamilies. Leukemia cells, due to differentiation and maturity disorders, are always accompanied by abnormal hyperplasia, and are stagnated at different stages of cell development. For example, acute leukemia (AL) cell differentiation is stagnated at the relatively earlier stages, and the majority of AL cells are progenitor cells and early immature cells; chronic leukemia (CL) cell differentiation is stagnated at the later stages, and the majority of CL cells are mature naive cells or mature cells. We hereby discuss the roles of STAT3 in the differentiation of leukemia cells as follows:

a) STAT3 in granulocyte differentiation and its role in leukemia. Granulocyte differentiation involves a variety of cytokines and transcription factors, of which G-CSF plays an essential role during the process. The binding of G-CSF to the G-CSF receptor (G-CSFR) causes the intracellular phosphorylation of the Y705 domain of STAT3 and the activation of multiple signal transduction pathways, including Ras/Raf/MAPK, PI3K and JAK/STAT cascades (53). In signaling transduction, the STAT3 protein regulates G-CSFR-mediated signaling pathways and inhibits granulocyte differentiation (54). Previous studies have suggested that STAT3 exerts inhibitory effects on granulocyte differentiation and maturation, since STAT3-deficient mice exhibit an increased ratio of mature to immature neutrophils in their bone marrow, peripheral blood and spleen following sustained exposure to G-CSF in vivo (55). Previous studies have reported that during granulopoiesis, the binding of G-CSF to G-CSFR activates STAT3, which subsequently stimulates the expression of CCAAT enhancer binding protein $(C / E B P \beta)$, promoting c-myc gene transcription, and thus inhibiting the differentiation of bone marrow 


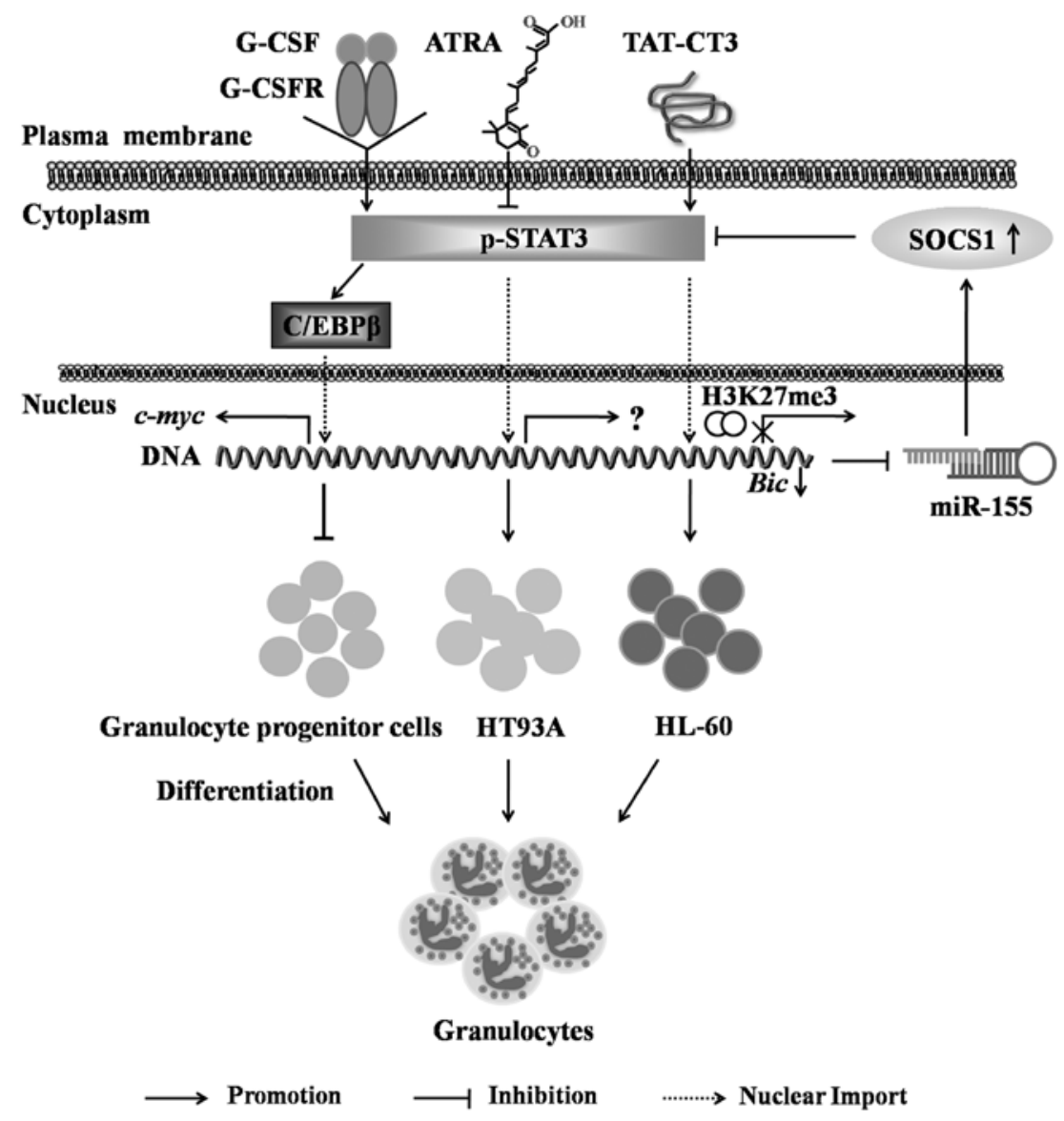

Figure 4. Roles of signal transducer and activator of transcription 3 (STAT3) in the processes of granulocyte progenitor cell/human acute promyelocytic leukemia cell differentiation into granulocytes. STAT3 regulates the G-CSFR-mediated signaling pathways and inhibits granulocyte differentiation, and the inhibition of STAT3 expression and activation can promote the granulocyte-oriented differentiation of leukemia cells.

granulocytic progenitors into granulocytes (54,56,57) (Fig. 4). However, it should be noted that isoforms of STAT3 may function differently during G-CSF-directed granulocyte differentiation. It has been reported that G-CSF activates STAT $3 \alpha$ in three of six uncultured AML patient samples and in all examined AML cell lines, apart from HL-60. G-CSF directs the differentiation of $\mathrm{CD}_{3} 4^{+}$bone marrow cells and HL-60 cells into granulocytes without affecting STAT3 $\alpha$ activity, but only increasing STAT3 $\beta$ activity. These results demonstrate that the balance of the two isoforms of STAT3 in myeloid cells may influence gene activation and the ability of these cells to differentiate in response to G-CSF (47). In addition, other researchers have revealed that the expression and activation of STAT3s is altered in a maturation stage-specific manner. During the process of granulocyte differentiation, the ratio of isoforms shifts from predominantly STAT3 $\alpha$ to STAT3 $\beta$. Concomitant with STAT $3 \alpha$ protein downregulation in different stages of granulocyte differentiation, the expression of STAT3 $\gamma$ is upregulated inversely. STAT3 $\delta$ protein is expressed at low levels and is reduced with differentiation, but is primarily phosphorylated during an intermediate stage of maturation (25).

The role of STAT3 in the process of leukemia cell differentiation into granulocytes is increasingly valued. $\mathrm{Xu}$ et al (58) observed that the fusion protein TAT-CT3 induced the committed differentiation of the human acute promyelocytic leukemia (APL) cell line, HL-60, into granulocytes, and
TAT-CT3 transiently promoted an elevation in STAT3 phosphorylation, which resulted in the STAT3 dimer entering the nucleus and promoting the expression of the Bic gene. STAT3 also plays a role in controlling the $\mathrm{H} 3 \mathrm{~K} 27 \mathrm{me} 3$ modification of the Bic gene promoter, through which it reduces Bic transcription, and suppresses $m i R-155$ transcription and finally results in an elevation in SOCS-1 levels, which further inhibits STAT3 phosphorylation in a feedback loop for a long-term period to promote HL-60 cell differentiation into granulocytes (58). Moreover, in another study, in the process of the all-trans retinoic acid (ATRA)-induced differentiation of the APL cell line, HT93A, into granulocytes, the expression levels of total and phosphorylated STAT3 were significantly reduced, which further suggested that the inhibition of STAT3 expression and activation would promote the granulocyte-oriented differentiation of leukemia cells (59). Thus, drugs or strategies that target STAT3 may hold promising prospects in modulating the granulocyte differentiation of leukemia cells (Fig. 4).

b) Involvement of STAT3 in monocyte/macrophage differentiation and its role in leukemia. Monocytes originate from granulocyte-monocyte progenitor cells in bone marrow and are transported through the blood; they migrate into the tissues, where they are transformed into macrophages, and macrophages can be polarized into two subgroups: M1 and M2. M1 macrophages mainly secrete tumor necrosis factor (TNF)- $\alpha$, interleukin (IL)-6 and other cytokines, exerting pro-inflammatory and antitumor effects; M2 macrophages, which are 


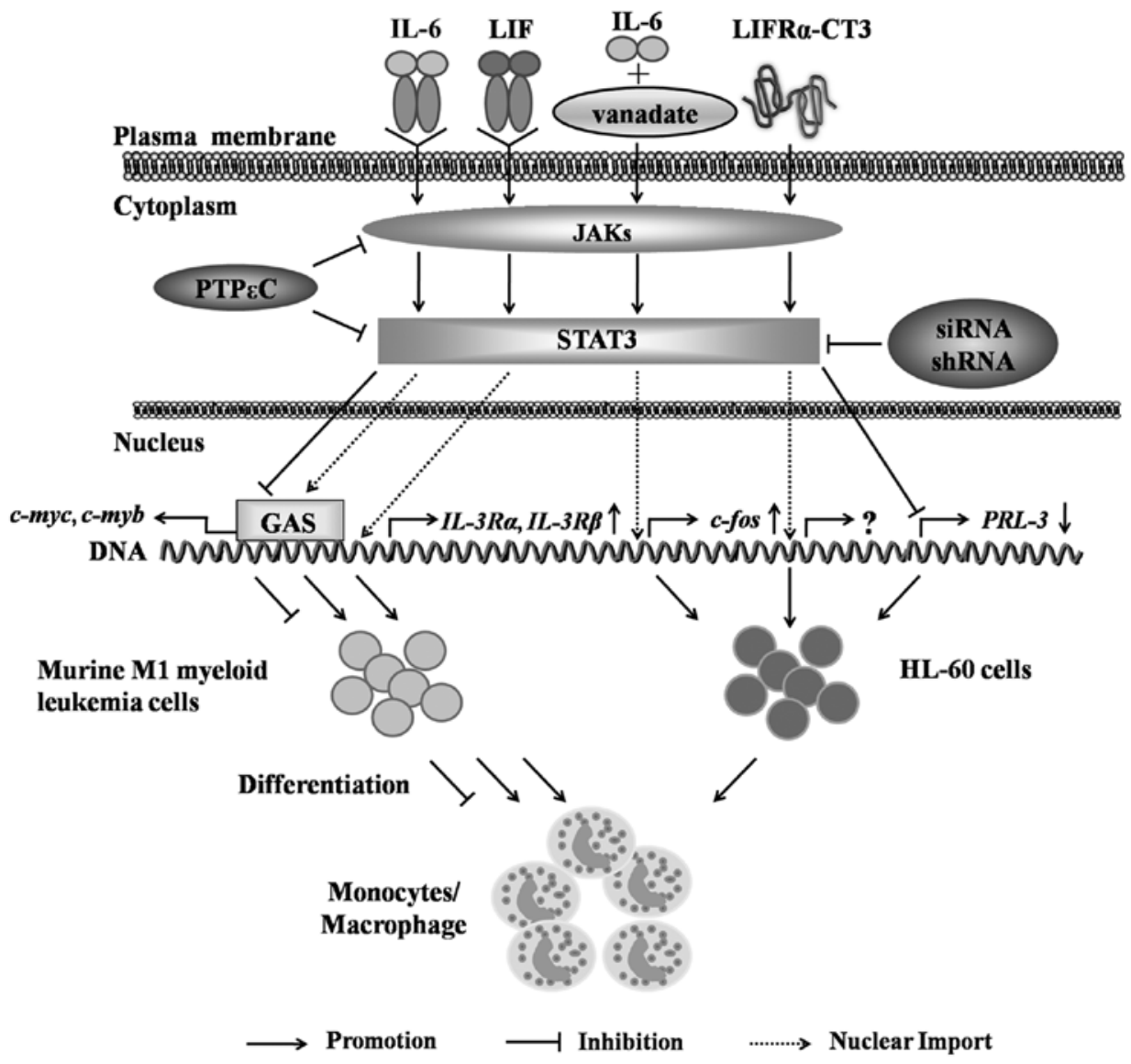

Figure 5. Roles of signal transducer and activator of transcription 3 (STAT3) in the differentiation of murine M1 myeloid leukemia cells/HL-60 cells into monocytes/macrophages. The dual roles of STAT3 were depicted in the regulation of leukemia cells differentiation into monocytes/macrophages.

characterized by the overexpression of arginase 1 and IL-4 receptor $\alpha(\mathrm{IL}-4 \mathrm{R} \alpha)$, mainly secrete IL-4, IL-10 and other cytokines, and play important roles in diverse biological processes, including anti-inflammation, tissue repair and tumor promotion (60-63). It has been reported that IL-6, in combination with macrophage colony stimulating factor (M-CSF), can induce $\mathrm{CD} 14^{+}$monocyte differentiation into M2-like phenotype macrophages in vitro, and during the process, the phosphorylated levels of STAT3 were found to be significantly increased, which suggests that STAT3 can induce the committed differentiation of mononuclear cells into M2 macrophages and exert pro-tumor functions (64). Moreover, Komohara et al (65) reported that upon co-culture with primary central nervous system lymphoma cells, macrophages exhibited a greater STAT3 phosphorylation and acquired the M2 phenotype, which indicated that STAT3 activation may also be involved in the promotion of macrophage M2 polarization, and tumor occurrence and development.

The roles of STAT3 in the process of leukemia cell differentiation into monocytes/macrophages have been increasingly investigated by researchers. It has been found that IL- 6 activates STAT3 to bind to and initiate the transcription of the target genes, $c-m y c$ and $c-m y b$, through the GAS sequence in the promoter, and thus promotes M1-type mouse myeloid leukemia cell differentiation into mononuclear cells. Moreover, leukemia inhibitory factor (LIF) promotes M1 mouse myeloid leukemia cell differentiation into macrophages by activating STAT3 and inducing $I L-3 R \alpha$ and $\beta$ subunit gene expression $(23,66,67)$. Furthermore, some studies have indicated that protein tyrosine phosphatase (PTP) epsilon C inhibits the activation of IL-6-mediated JAKs and STAT3 and the expression of their downstream target gene, $c$ - myc, thereby inhibiting the differentiation of M1 mouse myeloid leukemia cells into mononuclear cells (68) (Fig. 5).

In human HL-60 cells, the synergistic action of IL-6 with the PTP inhibitor, vanadate, can induce the expression of the differentiation gene $c$-fos by stimulating the IL-6/JAK/STAT3 signaling pathway to promote the differentiation of HL-60 cells into monocytes $(69,70)$. Leukemia inhibitory factor receptor-chain LIFR $\alpha$-CT3 activates STAT3 through the JAK2/STAT3 pathway, which leads to the expression of CD11b and CD14 on the surface of HL-60 cells and suggests that the activation of STAT3 can promote the differentiation of HL-60 cells into monocytes (71). However, studies have also found that the siRNA- or shRNA-mediated knockdown of STAT3 in HL-60 cells results in a decreased $P R L-3$ gene expression and an increased expression of the cell surface markers, CD11b and CD14, which indicates the dual roles of STAT3 in the regulation of leukemia cell differentiation; thus, the specific mechanisms warrant further investigation (72) (Fig. 5). However, STAT3 has yet not been validated to play a role in the process of leukemia cell differentiation into M1/M2 subgroup macrophages.

c) STAT3 in DC differentiation and its role in leukemia. Dendritic cells (DCs) originate from multifunctional hematopoietic stem cells, and are the most important antigen-presenting 
cells (APCs) in vivo, which play crucial roles in tumor surveillance, pathogenic microbial infection resistance and internal environmental stability maintenance $(73,74)$. Patients with leukemia with a defective DC number and function cannot effectively stimulate the adaptive immune response or eliminate leukemia cells (75). Thus, if the committed differentiation of leukemia cells into DCs could be induced, which would probably express leukemia-specific antigens on the membrane, this would directly present the leukemia antigens to the T-cells, and then kill leukemia cells (76). DC development is highly dependent upon fms-like tyrosine kinase 3 ligand/fms-like tyrosine kinase 3 (Flt3L/Flt3) signaling, and the interaction of Flt3L/Flt3 activates STAT3 via JAK, which subsequently promotes the transcription of regulatory factor E-box protein, and promotes DC differentiation (77-80). Brady et al (81) observed that STAT3 phosphorylation levels were significantly increased upon human granulocyte-macrophage colony stimulating factor (GM-CSF) and IL-4 treatment during the process of differentiation into DCs for the AML cell lines, HEL, KG-1 and MUTZ-3, which suggested that the constitutive STAT3 activation may promote the differentiation of leukemia cells into DCs and the intervention of STAT3 activity may have great prospects in modulating the process of the committed differentiation of leukemia cells into DCs for leukemia treatment.

STAT3 and leukemia cell apoptosis. The occurrence of leukemia is closely related to the apoptotic disorder of leukemia cells. STAT3 plays a key role in leukemia cell apoptosis. In general, STAT3 activation can inhibit the apoptosis of leukemia cells by inducing anti-apoptotic gene expression. For example, internal tandem duplication (ITD) in the juxtamembrane in the kinase domain of Flt 3 is a common genetic lesion in AML, and the stimulation of the Flt3-ITD AML cells, MV4-11, results in the elevation of p-STAT3 levels, which upregulates the expression of the anti-apoptotic gene, survivin, to protect AML cells from apoptosis (82). In the CML cell line, K562, the expression levels of the anti-apoptotic genes, Bcl-2, Bcl-xL, Mcl-1 and survivin and those of the inhibitor of apoptosis protein, c-IAP2, have been shown to be upregulated by STAT3 activation to protect K562 cells from apoptosis (83). In CLL cells, the expression levels of the anti-apoptotic genes, $B c l-2, B c l-x L$, cyclin D1 (CCNDI) and ROR1, were upregulated following the activation of STAT3, and protected CLL cells from apoptosis (84) (Fig. 6A). The inhibition of STAT3 expression can upregulate the expression of pro-apoptotic genes and induces leukemia cell apoptosis. For example, in K562 cells, the STAT3-specific inhibitor, LLL-3, has been shown to induce leukemia cell apoptosis by activating the caspase-3and -7-mediated pro-apoptotic pathway (85). In TEL-AML1 fused ALL, the STAT3 inhibitor, S3I-201, has been shown to induce leukemia cell apoptosis by upregulating the expression of the pro-apoptotic genes, caspase-3,p27 and p21 (86). The cytotoxic agent, bromo analogue ( $\mathrm{TBr}$ ), has been shown to enhance the expression of the pro-apoptotic genes caspase-3, -8 and -9 , and to decrease the ratio of the anti-apoptotic genes, Bcl-2/Bax, by downregulating p-STAT3 and upregulating p-ERK to induce the apoptosis of HL-60 cells (87). Moreover, (R)-5-hydroxy-2-methylchroman-4-one (HMC), isolated from a novel endophytic fungus, can significantly reduce the level of p-STAT3, which activates the pro-apoptotic genes,
Bax, Bid, caspase-3, - 8 and -9 to induce leukemia cell apoptosis (88) (Fig. 6B). However, a previous study reported that the overexpression of STAT3 in CLL upregulates caspase-3 expression, and induces CLL cell apoptosis (89), suggesting that the different activation status of STAT3 may play differential roles in the regulation of leukemia cell apoptosis.

In summary, STAT3 is closely related to the development of leukemia. It plays essential roles in the development of leukemia by promoting the proliferation of leukemia cells (Fig. 7A), regulating the differentiation of granulocytes, monocytes/macrophages and dendritic cells and blocking the apoptosis of leukemia cells (Fig. 7B and C). The STAT3 expression and activation status may thus be an important target for leukemia treatment and prognosis assessment.

\section{The roles of STAT3 in the diagnosis, treatment and prognosis of leukemia}

The sustained activation of the STAT3 gene plays an important role in the development of leukemia; it can be used as an important target in the early diagnosis, treatment and prognosis of leukemia.

The role of STAT3 in the diagnosis of leukemia. STAT3 plays an important role in the diagnosis of leukemia. For example, Xia et al (90) found that in patients newly diagnosed with AML, 13 out of 17 patients were found to exhibit the constitutive phosphorylation of STAT3 on Y705. Stevens et al (91) demonstrated that the STAT3 pathway was more sensitive to ligand stimulation in patients with relapsing AML. Benekli et al reported that constitutively active STAT3 was detected in ten of 36 patients newly diagnosed with AML (92), and in another study, almost $78 \%$ of the patients (21 of 27) expressed STAT3 $\beta$ protein (25).

Thus, collectively, it is suggested that STAT3 plays an important diagnostic role in both newly diagnosed and relapsing AML. T-cell large granular lymphocytic leukemia (T-LGLL) sustains the phosphorylation of STAT3, and mutations of the STAT3 gene have been identified as a recurrent genetic abnormality in T-LGLL (93-99).

STAT3 single nucleotide polymorphisms (SNPs) are also prospective candidates for use in predicting susceptibility to leukemia, which is associated with the individual sensitivity of leukemia and is important for leukemia diagnosis. For example, Zhong et al (100) investigated association between STAT3 SNPs and leukemia, and found that rs17886724 located on STAT3 intron 4 was closely related to the pathogenesis of leukemia; Lautner-Csorba et al (101) found that two SNPs of rs3816769 and rs12949918 in the STAT3 gene, were associated with a decreased risk of hyperdiploid ALL occurrence ( $\geq 50$ chromosomes). All these studies indicate the significance of STAT3 in the diagnosis of leukemia.

The role of STAT3 in the treatment of leukemia. STAT3 plays an important role in leukemia, and STAT3 intervention is currently a 'hot' topic of research, which may reveal novel targets and strategies for leukemia treatment $(102,103)$. At present, different types of STAT3 inhibitors have been implemented for leukemia treatment, including STAT3 SH2 domain inhibitors, DNA-binding domain inhibitors, STAT3 
$\mathbf{A}$

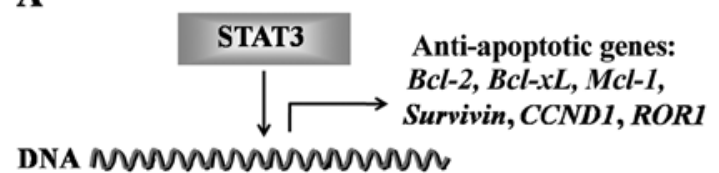

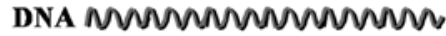

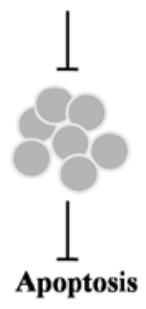

B

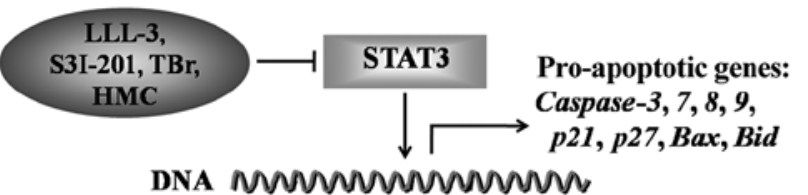

DNA munnounururn

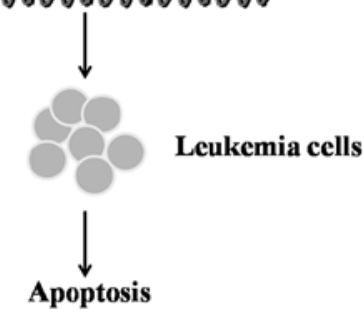

$\longrightarrow$ Promotion $\quad \longrightarrow$ Inhibition

Figure 6. Role of signal transducer and activator of transcription 3 (STAT3) in the apoptosis of leukemia cells. (A) STAT3 activation inhibits the apoptosis of leukemia cells by inducing anti-apoptotic gene expression. (B) The inhibition of STAT3 expression can upregulate the expression of pro-apoptotic genes and induces leukemia cell apoptosis.

A

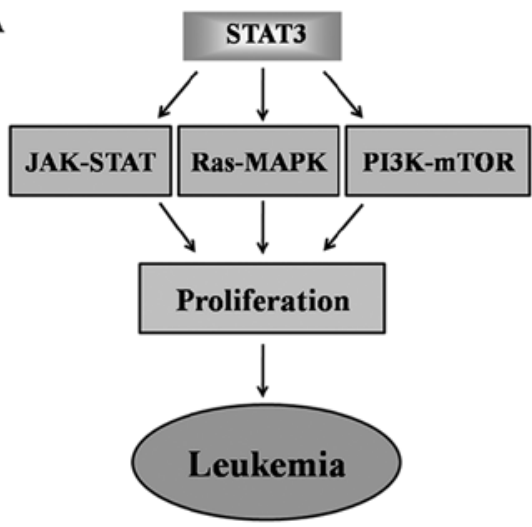

B

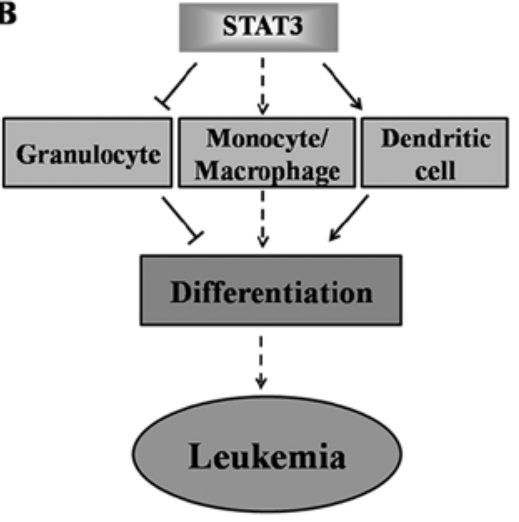

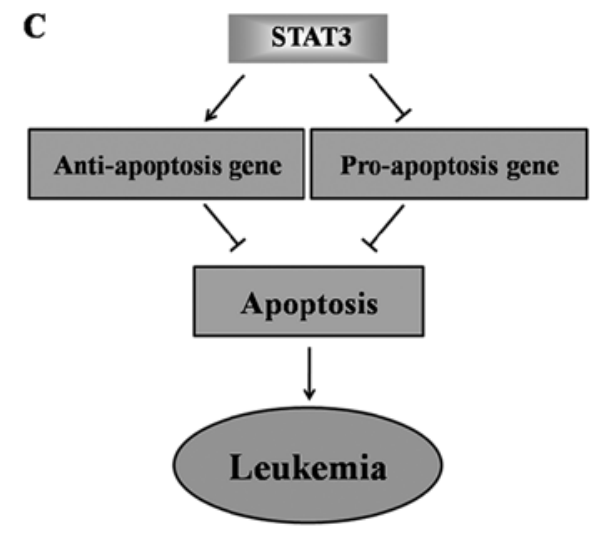

$--\rightarrow$ Tentative

Figure 7. Role of signal transducer and activator of transcription 3 (STAT3) in pathogenesis of leukemia. (A) STAT3 can promote the proliferation of leukemia cells via the Janus kinase (JAK)/STAT, Ras/mitogen-activated protein kinase (MAPK) and PI3K/mammalian target of rapamycin (mTOR) signaling pathways in the development of leukemia. (B) STAT3 plays essential roles in the development of leukemia by regulating the differentiation of granulocytes, monocytes/macrophages and dendritic cells. (C) STAT3 blocks the apoptosis of leukemia cells by inducing the expression of anti-apoptotic genes and by inhibiting that of pro-apoptotic genes in leukemia.

gene expression oligonucleotide inhibitors and $\mathrm{N}$-terminal domain inhibitors (104). For example, small molecule C188-9, a STAT3 inhibitor, has been shown to induce the apoptosis of multiple AML cell lines and primary cells (8). The STAT3 inhibitor, OPB-31121, has also been shown to strongly inhibit STAT3 and STAT5 phosphorylation, and to exert a significant anti-proliferative effect on human leukemia cells (105). In addition, a number of chemotherapy drugs can also target STAT3 to exert a therapeutic effect. For instance, decitabine has been shown to markedly inhibit the proliferation of HL-60 cells and to enhance the cytotoxicity of natural killer cells to HL-60 cells, which may be related to the STAT3 signaling pathway (106). Zoledronic acid and bortezomib can both inhibit the proliferation of K562 cells and induce apoptosis via the STAT3 signaling pathway $(107,108)$. Chidamide has been shown to affect AML cell viability by inhibiting the JAK2/STAT3 signaling pathway (109). Although some inhibitors have been shown to be effective in the treatment of leukemia in vitro, few inhibitors of STAT3 have been approved for leukemia therapy in clinical practice (Table II).

Moreover, many natural extracts of traditional Chinese medicine have also been shownt $\mathrm{o}$ inhibit the activation of STAT3 to exert antitumor effects. For instance, the traditional Chinese medicine, cucurbitacin B, has been shown to inhibit STAT3 activation along with the Raf/MEK/ERK pathway and to promote the apoptosis of K562 cells (110). It has also been demonstrated that dehydrocostus lactone significantly suppresses the proliferation of K562 cells by inhibiting STAT3 phosphorylation and the expression of downstream target genes (111). Tanshinone IIA and cryptotanshinone have been shown to induce K562 cell apoptosis by modulating JAK/STAT3/5 and SHP1/2 signaling distinctively (112). Matrine suppresses the growth of human CLL cells via its inhibition of the IL-6/JAK/STAT3 signaling (113). On the whole, traditional Chinese medicine has great potential in the treatment of leukemia. It has also been reported that certain biological 
Table II. STAT3 inhibitors.

\begin{tabular}{lll}
\hline STAT3 & \multicolumn{1}{c}{$\begin{array}{c}\text { Targeted } \\
\text { domain }\end{array}$} & $\begin{array}{c}\text { Effect on leukemia } \\
\text { treatment } \\
\text { (pre-clinical) }\end{array}$ \\
\hline ST3-H2A2 & The N-terminal & Unknown \\
BP-1-102 & The SH2 & Unknown \\
BP-5-087 & The SH2 & Yes \\
Catechol & The SH2 & Unknown \\
C188-9 & The SH2 & Yes \\
ISS 610 & The SH2 & Unknown \\
LLL-3 & The SH2 & Yes \\
LLL12 & The SH2 & Unknown \\
MM-206 & The SH2 & Yes \\
OPB-31121 & The SH2 & Yes \\
OPB-51602 & The SH2 & Yes \\
STA-21 & The SH2 & Yes \\
Stattic & The SH2 & Yes \\
S3I-201 & The SH2 & Unknown \\
S3I-201.1066 & The SH2 & Unknown \\
S3I-M2001 & The SH2 & Unknown \\
STX-0119 & The SH2 & Yes \\
S3I-1757 & The SH2 & Unknown \\
5,15-DPP & The SH2 & Unknown \\
CPA-1 & DNA binding & Unknown \\
CPA-7 & DNA binding & Unknown \\
DBD-1 & DNA binding & Unknown \\
InS3-54 & DNA binding & Unknown \\
IS3-295 & DNA binding & Unknown \\
tetrachloride & DNA binding & \\
Atovaquone & Unknown & Yes \\
\hline
\end{tabular}

therapies can also be used to target STAT3 signaling pathways for leukemia treatment. Lentivirus-mediated STAT3 silencing may inhibit the expression of its downstream genes, $c-m y c$, $B c l-x L$ and cyclin D1, to suppress the malignant biological behaviors, and STAT3 silencing also inhibits the leukemogenic potency of K562 cells in mice (114). Moreover, the suppression of the survivin gene induced by the BCR/ABL/JAK2/STAT3 pathway sensitizes imatinib-resistant CML cells to different cytotoxic drugs (115). Thus, the role of biological therapy in the treatment of leukemia cannot be ignored.

The role of STAT3 in the prognosis of leukemia. The roles of STAT3 in the prognosis of leukemia have drawn increasing attentions, but are still controversial. Recent studies have found that $\mathrm{Mcl}-1$ gene expression and indoleamine 2,3-dioxygenase 1 (IDO1) activity can both be regulated by STAT3 which are associated with the poorer prognosis of leukemia $(116,117)$. Bruserud et al (103) examined the association between STAT3 expression in bone marrow and the prognosis of patients with AML, and found that STAT3 expression and Y705 activation had an adverse prognostic impact on human AML. Moreover, Adamaki et al (118) discovered that 8 out of 14 childhood patients with ALL, in which STAT1 and STAT3 were expressed at lower levels on day 33, were relapse-free with a high survival rate, indicating that $S T A T 3$ gene upregulation is a poor predictor of the clinical prognosis of childhood ALL. Furthermore, Zhong et al (119) investigated the association between genomic polymorphisms of STAT3 and AML patient response to chemotherapy in a Chinese population, and found that there were strong associations between unfavorable cytogenetics, partial remission (and even no remission) and GG genotype frequency in rs9909659, which suggested that the STAT3 GG genotype in rs9909659 may confer an enhanced resistance to standard chemotherapy, and predict an unfavorable prognosis. Besides, it has also been reported that constitutive STAT3 activation is associated with the shortest disease-free survival in AML, and the subgroup of AML patients, which expressed STAT3 $\beta$ and showed constitutive activity of STAT3, experienced a particularly poor outcome (92).

By contrast, some studies have suggested that p-STAT3 also has a beneficial effect on the prognosis of leukemia. Redell et al $(8,120)$ discovered that when the phosphorylated level of STAT3 on Y705 and S727 increased in AML upon cytokine stimulation, the disease-free and survival rates of patients were improved. Levidou et al (121) discovered that the immunoreactivity of tyrosine phosphorylated STAT3 was marginally associated with a prolonged overall survival. In addition, the upregulation of tyrosine phosphorylated STAT3 was associated with a longer time to first treatment, and the absence of p-STAT3 was associated with a shorter time to progression, which indicated that p-STAT3 also has a favorable prognostic effect on leukemia. Nevertheless, the upregulation of STAT3 is also associated with the favorable prognosis of AL (122). Collectively, the impact of STAT3 on the prognosis of leukemia remains controversial. Due to the defects of current clinical studies, including small sample sizes and so on, extensive clinical studies are warranted in order to further confirm the role of STAT3 in the evaluation of the prognosis of leukemia.

\section{Conclusion}

STAT3 is an important signal transducer and activator of transcription, which is widely involved in cell physiological processes, such as cell proliferation, differentiation and apoptosis through a variety of signal transduction pathways, and plays key roles in the occurrence of cancer and other diseases. In this review, the roles of STAT3 in the pathogenesis, diagnosis, treatment and prognosis of leukemia were reviewed and discussed in the aspects of cell proliferation, committed cell differentiation and apoptosis. There is increasing evidence to indicate that STAT3 expression and activity abnormalities will lead to excessive proliferation, differentiation disorders and the abnormal apoptosis of leukemia cells, which may provide a novel new biomarker for the clinical diagnosis, treatment and prognosis evaluation of leukemia. At present, the roles of upstream factors modulating STAT3 expression and activity, and the signaling pathways mediated by downstream target genes are not yet clear during the process of leukemia development. The in-depth exploration of this area, particularly in the perspective of epigenetic regulation, may further reveal the roles of STAT3 in the pathogenesis of leukemia and the essential regulatory mechanisms. 


\section{Acknowledgements}

Not applicable.

\section{Funding}

This study was supported by the Natural Science Foundation of China (grant nos. 81373670, 81673981, 81573467, 81601442 and 81704116), the Primary Research and Development Plan of Shandong Province (grant nos.2016GSF202016,2017GSF19118 and 2017GSF218013), the Project of Transformation in High-tech Achievements (grant no. 2013ZHZX2A0405), the Natural Science Foundation of Shandong Province (grant no. ZR2017PH008 and ZR2018PH042), the Science and Technology Development Grant of the State Administration of traditional Chinese medicine of Shandong Province (grant nos. 2013-2016 and 2017-174), the Family Planning Committee of Shandong Province [grant no. (2014)14], the Project for Shandong Medical and Health Science and Technology Plan (grant no. 2015WS0191 and 2016WS0524), the Project of Science and Technology of Shandong Academy of Medical Sciences (grant nos. 2016-34, 2016-35 and 2017-15) and the Innovation Project of Shandong Academy of Medical Sciences.

\section{Availability of data and materials}

All data generated or analyzed during this study are included in this published article.

\section{Authors' contributions}

YS, ZZ, XQ, XZ and LZ searched the literature for STAT3 roles in leukemia; RW, XY and YZ screened the literature for STAT3 inhibitors; YS, ZZ, QG and LS drew the graphics; XL conceived the project, and YS, ZZ and XL wrote the manuscript. All authors have read and approved the final manuscript.

\section{Ethics approval and consent to participate}

Not applicable.

\section{Consent for publication}

Not applicable.

\section{Competing interests}

The authors declare that they have no competing interests.

\section{References}

1. Chen WQ, Shan BE, Zheng SR, Lin GZ, Chen JZ, Chen JG and He YT: Analysis of incidence and mortality of leukemia in registration areas of China from 2003 to 2007. Tumor 32: 251-255, 2012 (In Chinese)

2. Amitay EL and Keinan-Boker L: Breastfeeding and childhood leukemia incidence: Ameta-analysis and systematic review. JAMA Pediatr 169: e151025, 2015.

3. Redaelli A, Stephens JM, Laskin BL, Pashos CL and Botteman MF: The burden and outcomes associated with four leukemias: AML, ALL, CLL and CML. Expert Rev Anticancer Ther 3: 311-329, 2003
4. Namanja AT, Wang J, Buettner R, Colson L and Chen Y: Allosteric communication across STAT3 domains associated with STAT3 function and disease-causing mutation. J Mol Biol 428: 579-589, 2016.

5. Yu H, Kortylewski M and Pardoll D: Crosstalk between cancer and immune cells: Role of STAT3 in the tumour microenvironment. Nat Rev Immunol 7: 41-51, 2007.

6. Yu H and Jove R: The STATs of cancer - new molecular targets come of age. Nat Rev Cancer 4: 97-105, 2004.

7. Villarino AV, Kanno Y,Ferdinand JR and O'Shea JJ: Mechanisms of Jak/STAT signaling in immunity and disease. J Immunol 194: 21-27, 2015.

8. Redell MS, Ruiz MJ, Alonzo TA, Gerbing RB and Tweardy DJ: Stat3 signaling in acute myeloid leukemia: Ligand-dependent and -independent activation and induction of apoptosis by a novel small-molecule Stat3 inhibitor. Blood 117: 5701-5709, 2011

9. Benekli M, Xia Z, Donohue KA, Ford LA, Pixley LA, Baer MR, Baumann $\mathrm{H}$ and Wetzler M: Constitutive activity of signal transducer and activator of transcription 3 protein in acute myeloid leukemia blasts is associated with short disease-free survival. Blood 99: 252-257, 2002.

10. Rezvani K and Barrett J: STAT3: The 'Achilles' heel for AML? Blood 123: 1-2, 2014.

11. Redell MS: A STAT3 decoy lures AML out of hiding. Blood 127: 1628-1629, 2016.

12. Yue P and Turkson J: Targeting STAT3 in cancer: How successful are we? Expert Opin Investig Drugs 18: 45-56, 2009.

13. Zhang T, Kee WH, Seow KT, Fung W and Cao X: The coiled-coil domain of Stat 3 is essential for its $\mathrm{SH} 2$ domain-mediated receptor binding and subsequent activation induced by epidermal growth factor and interleukin-6. Mol Cell Biol 20: 7132-7139, 2000.

14. Seidel HM, Milocco LH, Lamb P, Darnell JE Jr, Stein RB and Rosen J: Spacing of palindromic half sites as a determinant of selective STAT (signal transducers and activators of transcription) DNA binding and transcriptional activity. Proc Natl Acad Sci USA 92: 3041-3045, 1995.

15. Song L and Shen BF: New development on Jak/STAT sigal transduction pathway. Immunol J 16: 68-71, 2000. (In Chinese).

16. Dewilde S, Vercelli A, Chiarle R and Poli V: Of alphas and betas: Distinct and overlapping functions of STAT3 isoforms. Front Biosci 13: 6501-6514, 2008.

17. Kim BH, Yi EH and Ye SK: Signal transducer and activator of transcription 3 as a therapeutic target for cancer and the tumor microenvironment. Arch Pharm Res 39: 1085-1099, 2016.

18. Ren Z, Mao X, Mertens C, Krishnaraj R, Qin J, Mandal PK, Romanowski MJ, McMurray JS and Chen X: Crystal structure of unphosphorylated STAT3 core fragment. Biochem Biophys Res Commun 374: 1-5, 2008.

19. Chakraborty A and Tweardy DJ: Stat 3 and G-CSF-induced myeloid differentiation. Leuk Lymphoma 30: 433-442, 1998.

20. Ilaria RL Jr: STAT isoforms: Mediators of STAT specificity or leukemogenesis? Leuk Res 25: 483-484, 2001.

21. Becker S, Groner B and Müller CW: Three-dimensional structure of the Stat3beta homodimer bound to DNA. Nature 394: 145-151, 1998.

22. Benekli M, Baer MR, Baumann H and Wetzler M: Signal transducer and activator of transcription proteins in leukemias. Blood 101: 2940-2954, 2003.

23. Coffer PJ, Koenderman L and de Groot RP: The role of STATs in myeloid differentiation and leukemia. Oncogene 19: 2511-2522, 2000.

24. Chakraborty A and Tweardy DJ: Granulocyte colony-stimulating factor activates a 72-kDa isoform of STAT3 in human neutrophils. J Leukoc Biol 64: 675-680, 1998.

25. Hevehan DL, Miller WM and Papoutsakis ET: Differential expression and phosphorylation of distinct STAT3 proteins during granulocytic differentiation. Blood 99: 1627-1637, 2002.

26. Pilati C and Zucman-Rossi J: Mutations leading to constitutive active gp130/JAK1/STAT3 pathway. Cytokine Growth Factor Rev 26: 499-506, 2015.

27. Bowman T, Garcia R, Turkson J and Jove R: STATs in oncogenesis. Oncogene 19: 2474-2488, 2000.

28. Groner B, Lucks $P$ and Borghouts C: The function of Stat 3 in tumor cells and their microenvironment. Semin Cell Dev Biol 19: 341-350, 2008

29. Takeda K, Kaisho T, Yoshida N, Takeda J, Kishimoto T and Akira S: Correction: Stat 3 activation is responsible for IL-6dependent $\mathrm{T}$ cell proliferation through preventing apoptosis: generation and characterization of T cell-specific Stat3-deficient mice. J Immunol 194: 3526, 2015. 
30. Levy DE and Lee CK: What does Stat3 do? J Clin Invest 109: $1143-1148,2002$

31. Bournazou E and Bromberg J: Targeting the tumor microenvironment: JAK-STAT3 signaling. JAK-STAT 2: e23828, 2013.

32. Guo H, Zhou H, Lu J, Qu Y, Yu D and Tong Y: Vascular endothelial growth factor: An attractive target in the treatment of hypoxic/ ischemic brain injury. Neural Regen Res 11: 174-179, 2016.

33. Leonard WJ and O'Shea JJ: Jaks and STATs: Biological implications. Annu Rev Immunol 16: 293-322, 1998

34. Schindler C and Strehlow I: Cytokines and STAT signaling. Adv Pharmacol 47: 113-174, 2000

35. Kisseleva T, Bhattacharya S, Braunstein J and Schindler CW: Signaling through the JAK/STAT pathway, recent advances and future challenges. Gene 285: 1-24, 2002.

36. Kang SK, Kang KS, Jee MK and Kim BS: Vascular endothelial growth factor/kinase insult domain receptor (KDR)/fetal liver kinase 1 (FLK1)-mediated skin-epithelial progenitor cells reprogramming. Tissue Eng Part A 16: 2687-2697, 2010.

37. Pastuschek J, Poetzsch J, Morales-Prieto DM, Schleussner E, Markert UR and Georgiev G: Stimulation of the JAK/STAT pathway by LIF and OSM in the human granulosa cell line COV434. J Reprod Immunol 108: 48-55, 2015.

38. Marino VJ and Roguin LP: The granulocyte colony stimulating factor (G-CSF) activates Jak/STAT and MAPK pathways in a trophoblastic cell line. J Cell Biochem 103: 1512-1523, 2008.

39. Platanias LC: Mechanisms of type-I- and type-II-interferonmediated signalling. Nat Rev Immunol 5: 375-386, 2005.

40. Kijima T, Niwa H, Steinman RA, Drenning SD, Gooding WE, Wentzel AL, Xi S and Grandis JR: STAT3 activation abrogates growth factor dependence and contributes to head and neck squamous cell carcinoma tumor growth in vivo. Cell Growth Differ 13: 355-362, 2002.

41. Ram PT and Iyengar R: G protein coupled receptor signaling through the Src and Stat 3 pathway: Role in proliferation and transformation. Oncogene 20: 1601-1606, 2001

42. Ahmed ST and Ivashkiv LB: Inhibition of IL-6 and IL-10 signaling and Stat activation by inflammatory and stress pathways. J Immunol 165: 5227-5237, 2000.

43. Trengove MC and Ward AC: SOCS proteins in development and disease. Am J Clin Exp Immunol 2: 1-29, 2013.

44. Piessevaux J, Lavens D, Peelman F and Tavernier J: The many faces of the SOCS box. Cytokine Growth Factor Rev 19: 371-381, 2008.

45. Shuai K: Regulation of cytokine signaling pathways by PIAS proteins. Cell Res 16: 196-202, 2006.

46. Ma LD, Zhou M, Wen SH, Ni C, Jiang LJ, Fan J and Xia L: Effects of STAT3 silencing on fate of chronic myelogenous leukemia K562 cells. Leuk Lymphoma 51: 1326-1336, 2010.

47. Chakraborty A, White SM, Schaefer TS, Ball ED, Dyer KF and Tweardy DJ: Granulocyte colony-stimulating factor activation of Stat 3 alpha and Stat3 beta in immature normal and leukemic human myeloid cells. Blood 88: 2442-2449, 1996.

48. Quotti Tubi L, Canovas Nunes S, Brancalion A,Doriguzzi Breatta E, Manni S, Mandato E, Zaffino F, Macaccaro P, Carrino M Gianesin K, et al: Protein kinase CK2 regulates AKT, NF- $\kappa B$ and STAT3 activation, stem cell viability and proliferation in acute myeloid leukemia. Leukemia 31: 292-300, 2017

49. Mencalha AL, Binato R, Ferreira GM, Du Rocher B and Abdelhay E: Forkhead box M1 (FoxM1) gene is a new STAT3 transcriptional factor target and is essential for proliferation, survival and DNA repair of K562 cell line. PLoS One 7: e48160, 2012.

50. Yuzugullu H, Von T, Thorpe LM, Walker SR, Roberts TM, Frank DA and Zhao JJ: NTRK2 activation cooperates with PTEN deficiency in T-ALL through activation of both the PI3K-AKT and JAK-STAT3 pathways. Cell Discov 2: 16030, 2016

51. Cook AM, Li L, Ho Y, Lin A, Li L, Stein A, Forman S, Perrotti D, Jove R and Bhatia R: Role of altered growth factor receptormediated JAK2 signaling in growth and maintenance of human acute myeloid leukemia stem cells. Blood 123: 2826-2837, 2014.

52. Sasaki R, Ito S, Asahi M and Ishida Y: YM155 suppresses cell proliferation and induces cell death in human adult T-cell leukemia/lymphoma cells. Leuk Res 39: 1473-1479, 2015.

53. Avalos BR: Molecular analysis of the granulocyte colonystimulating factor receptor. Blood 88: 761-777, 1996

54. Hillmer EJ, Zhang H, Li HS and Watowich SS: STAT3 signaling in immunity. Cytokine Growth Factor Rev 31: 1-15, 2016.

55. Panopoulos AD, Zhang L, Snow JW, Jones DM, Smith AM, El Kasmi KC, Liu F, Goldsmith MA, Link DC, Murray PJ, et al STAT3 governs distinct pathways in emergency granulopoiesis and mature neutrophils. Blood 108: 3682-3690, 2006.
56. Krönke M, Schlüter C and Pfizenmaier K: Tumor necrosis factor inhibits MYC expression in HL-60 cells at the level of mRNA transcription. Proc Natl Acad Sci USA 84: 469-473, 1987.

57. Johansen LM, Iwama A, Lodie TA, Sasaki K, Felsher DW, Golub TR and Tenen DG: c-Myc is a critical target for c/EBPalpha in granulopoiesis. Mol Cell Biol 21: 3789-3806, 2001.

58. Xu S, Xu Z, Liu B, Sun Q, Yang L, Wang J, Wang Y and Liu H: LIFR $\alpha$-CT3 induces differentiation of a human acute myelogenous leukemia cell line HL-60 by suppressing miR-155 expression through the JAK/STAT pathway. Leuk Res 38: $1237-1244,2014$

59. Uchino Y, Iriyama N, Hatta Y and Takei M: Granulocyte colonystimulating factor potentiates all-trans retinoic acid-induced granulocytic differentiation in acute promyelocytic leukemia cell line HT93A. Cancer Cell Int 15: 30, 2015.

60. Xu N, Tang XH, Pan W, Xie ZM, Zhang GF, Ji MH, Yang JJ, Zhou MT and Zhou ZQ: Spared nerve injury increases the expression of microglia M1 markers in the prefrontal cortex of rats and provokes depression-like behaviors. Front Neurosci 11: 209, 2017.

61. Allman WR, Dey R, Liu L, Siddiqui S, Coleman AS, Bhattacharya P, Yano M, Uslu K, Takeda K, Nakhasi HL, et al: TACI deficiency leads to alternatively activated macrophage phenotype and susceptibility to Leishmania infection. Proc Natl Acad Sci USA 112: E4094-E4103, 2015.

62. Zhou L, Zhuo H, Ouyang H, Liu Y, Yuan F, Sun L, Liu F and Liu H: Glycoprotein non-metastatic melanoma protein b (Gpnmb) is highly expressed in macrophages of acute injured kidney and promotes M2 macrophages polarization. Cell Immunol 316: 53-60, 2017.

63. Binnemars-Postma K, Storm G and Prakash J: Nanomedicine strategies to target tumor-associated macrophages. Int J Mol Sci 18: 979, 2017.

64. Fu XL, Duan W, Su CY, Shen XQ, Zhuang Y, Yu PW and Zhao YL: IL-6 cooperated with M-CSF induce CD14 ${ }^{+}$monocytes differentiation into M2-like phenotype macrophages in vitro. Immunol J 32: 1013-1018, 2016 (In Chinese).

65. Komohara Y, Horlad H, Ohnishi K, Ohta K, Makino K, Hondo H, Yamanaka R, Kajiwara K, Saito T, Kuratsu J, et al: M2 macrophage/microglial cells induce activation of Stat3 in primary central nervous system lymphoma. J Clin Exp Hematop 51: 93-99, 2011

66. Mangan JK, Rane SG, Kang AD, Amanullah A, Wong BC and Reddy EP: Mechanisms associated with IL-6-induced up-regulation of Jak3 and its role in monocytic differentiation. Blood 103: 4093-4101, 2004.

67. Iwamoto $T$, Senga $T$, Adachi $K$ and Hamaguchi $M$ : Stat3-dependent induction of interleukin-3 receptor expression in leukemia inhibitory factor-stimulated M1 mouse leukemia cells. Cytokine 25: 136-139, 2004.

68. Tanuma N, Nakamura K, Shima H and Kikuchi K: Proteintyrosine phosphatase PTPepsilon C inhibits Jak-STAT signaling and differentiation induced by interleukin- 6 and leukemia inhibitory factor in M1 leukemia cells. J Biol Chem 275 : 28216-28221, 2000.

69. Yao Y, Zhou Q and Ericson SG: Vanadate stimulates monocytic differentiation activity of IL- 6 by enhancing actin filament polymerization in HL-60 cells. J Biomed Sci 11: 940-949, 2004.

70. Woetmann A, Nielsen M, Christensen ST, Brockdorff J, Kaltoft K Engel AM, Skov S, Brender C, Geisler C, Svejgaard A, et al: Inhibition of protein phosphatase $2 \mathrm{~A}$ induces serine/threonine phosphorylation, subcellular redistribution, and functional inhibition of STAT3. Proc Natl Acad Sci USA 96: 10620-10625, 1999.

71. Sun Q, Wang J, Xiong J, Yang L and Liu H: Free LIF receptor $\alpha$-chain distal cytoplasmic motifs enhance Jak2independent STAT3 phosphorylation and induce differentiation in HL-60 cells. Oncol Rep 26: 399-404, 2011

72. Zhou J, Chong PS, Lu X, Cheong LL, Bi C, Liu SC, Zhou Y, Tan TZ, Yang H, Chung TH, et al: Phosphatase of regenerating liver-3 is regulated by signal transducer and activator of transcription 3 in acute myeloid leukemia. Exp Hematol 42: 1041-1052.e1-2, 2014.

73. Banchereau J, Briere F, Caux C, Davoust J, Lebecque S, Liu YJ, Pulendran B and Palucka K: Immunobiology of dendritic cells. Annu Rev Immunol 18: 767-811, 2000.

74. Liu YJ, Kanzler H, Soumelis V and Gilliet M: Dendritic cell lineage, plasticity and cross-regulation. Nat Immunol 2: 585-589, 2001 . 
75. Mohty M, Jarrossay D, Lafage-Pochitaloff M,Zandotti C,Brière F, de Lamballeri XN, Isnardon D, Sainty D, Olive D and Gaugler B: Circulating blood dendritic cells from myeloid leukemia patients display quantitative and cytogenetic abnormalities as well as functional impairment. Blood 98: 3750-3756, 2001.

76. Claxton DF, McMannis J, Champlin R and Choudhury A: Therapeutic potential of leukemia-derived dendritic cells: Preclinical and clinical progress. Crit Rev Immunol 21: 147-155, 2001.

77. Wu L and Liu YJ: Development of dendritic-cell lineages. Immunity 26: 741-750, 2007.

78. McKenna HJ, Stocking KL, Miller RE, Brasel K, De Smedt T, Maraskovsky E, Maliszewski CR, Lynch DH, Smith J, Pulendran B, et al: Mice lacking flt3 ligand have deficient hematopoiesis affecting hematopoietic progenitor cells, dendritic cells, and natural killer cells. Blood 95: 3489-3497, 2000.

79. Waskow C, Liu K, Darrasse-Jèze G, Guermonprez P, Ginhoux F, Merad M, Shengelia T, Yao K and Nussenzweig M: The receptor tyrosine kinase Flt3 is required for dendritic cell development in peripheral lymphoid tissues. Nat Immunol 9: 676-683, 2008

80. Li HS, Yang CY, Nallaparaju KC, Zhang H, Liu YJ, Goldrath AW and Watowich SS: The signal transducers STAT5 and STAT3 control expression of Id 2 and E2-2 during dendritic cell development. Blood 120: 4363-4373, 2012.

81. Brady MT, Miller A, Sait SN, Ford LA, Minderman H, Wang ES Lee KP, Baumann $\mathrm{H}$ and Wetzler M: Down-regulation of signal transducer and activator of transcription 3 improves human acute myeloid leukemia-derived dendritic cell function. Leuk Res 37: 822-828, 2013

82. Zhou J, Bi C, Janakakumara JV, Liu SC, Chng WJ, Tay KG, Poon LF, Xie Z, Palaniyandi S, Yu H, et al: Enhanced activation of STAT pathways and overexpression of survivin confer resistance to FLT3 inhibitors and could be therapeutic targets in AML. Blood 113: 4052-4062, 2009.

83. Nair RR, Tolentino JH and Hazlehurst LA: Role of STAT3 in transformation and drug resistance in CML. Front Oncol 2: 30, 2012.

84. Li P, Harris D, Liu Z, Rozovski U, Ferrajoli A, Wang Y, Bueso-Ramos C, Hazan-Halevy I, Grgurevic S, Wierda W, et al: STAT3-activated GM-CSFR $\alpha$ translocates to the nucleus and protects CLL cells from apoptosis. Mol Cancer Res 12 1267-1282, 2014

85. Mencalha AL, Du Rocher B, Salles D, Binato R and Abdelhay E: LLL-3, a STAT3 inhibitor, represses BCR-ABL-positive cell proliferation, activates apoptosis and improves the effects of Imatinib mesylate. Cancer Chemother Pharmacol 65: 1039-1046, 2010.

86. Mangolini M, de Boer J, Walf-Vorderwülbecke V, Pieters R, den Boer ML and Williams O: STAT3 mediates oncogenic addiction to TEL-AML1 in $\mathrm{t}(12 ; 21)$ acute lymphoblastic leukemia. Blood 122: 542-549, 2013.

87. Pathania AS, Kumar S, Guru SK, Bhushan S, Sharma PR Aithagani SK, Singh PP, Vishwakarma RA, Kumar A and Malik F: The synthetic tryptanthrin analogue suppresses STAT3 signaling and induces caspase dependent apoptosis via ERK up regulation in human leukemia HL-60 cells. PLoS One 9 e110411, 2014.

88. Pathania AS, Guru SK, Ul Ashraf N, Riyaz-Ul-Hassan S, Ali A, Abdullah Tasduq S, Malik F and Bhushan S: A novel stereo bioactive metabolite isolated from an endophytic fungus induces caspase dependent apoptosis and STAT-3 inhibition in human leukemia cells. Eur J Pharmacol 765: 75-85, 2015.

89. Rozovski U, Harris DM, Li P, Liu Z, Wu JY, Grgurevic S, Faderl S, Ferrajoli A, Wierda WG, Martinez M, et al: At high levels, constitutively activated STAT3 induces apoptosis of chronic lymphocytic leukemia cells. J Immunol 196: 4400-4409, 2016.

90. Xia Z, Sait SN, Baer MR, Barcos M, Donohue KA, Lawrence D, Ford LA, Block AM, Baumann H and Wetzler M: Truncated STAT proteins are prevalent at relapse of acute myeloid leukemia. Leuk Res 25: 473-482, 2001

91. Stevens AM, Ruiz MJ, Gerbing RB, Alonzo TA, Gamis AS and Redell MS: Ligand-induced STAT3 signaling increases at relapse and is associated with outcome in pediatric acute myeloid leukemia: A report from the Children's Oncology Group. Haematologica 100: e496-e500, 2015

92. Benekli M1: Xia Z, Donohue KA, Ford LA, Pixley LA Baer MR, Baumann $\mathrm{H}$ and Wetzler M: Constitutive activity of signal transducer and activator of transcription 3 protein in acute myeloid leukemia blasts is associated with short disease-free survival. Blood 2002: 252-257, 2002.
93. Kristensen T, Larsen M, Rewes A, Frederiksen H, Thomassen M and Møller MB: Clinical relevance of sensitive and quantitative STAT3 mutation analysis using next-generation sequencing in T-cell large granular lymphocytic leukemia. J Mol Diagn 16 382-392, 2014.

94. Jerez A, Clemente MJ, Makishima H, Koskela H, Leblanc F, Peng Ng K, Olson T, Przychodzen B, Afable M, Gomez-Segui I, et al: STAT3 mutations unify the pathogenesis of chronic lymphoproliferative disorders of NK cells and T-cell large granular lymphocyte leukemia. Blood 120: 3048-3057, 2012.

95. Rajala HL, Olson T, Clemente MJ, Lagström S, Ellonen P, Lundan T,Hamm DE,Zaman SA, Lopez Marti JM, Andersson EI, et al: The analysis of clonal diversity and therapy responses using STAT3 mutations as a molecular marker in large granular lymphocytic leukemia. Haematologica 100: 91-99, 2015.

96. Lamy T and Loughran TP Jr: How I treat LGL leukemia. Blood 117: 2764-2774, 2011.

97. Lamy T, Moignet A and Loughran TP Jr: LGL leukemia: From pathogenesis to treatment. Blood 129: 1082-1094, 2017.

98. Matutes E: Large granular lymphocytic leukemia. Current diagnostic and therapeutic approaches and novel treatment options. Expert Rev Hematol 10: 251-258, 2017.

99. Ohgami RS, Ma L, Merker JD, Martinez B, Zehnder JL and Arber DA: STAT3 mutations are frequent in $\mathrm{CD}^{+} 0^{+} \mathrm{T}$-cell lymphomas and T-cell large granular lymphocytic leukemia. Leukemia 27: 2244-2247, 2013.

100. Zhong Y, Wu J, Chen B, Ma R, Cao H, Wang Z, Cheng L, Ding J and Feng J: Investigation and analysis of single nucleotide polymorphisms in Janus kinase/signal transducer and activator of transcription genes with leukemia. Leuk Lymphoma 53: 1216-1221, 2012.

101.Lautner-Csorba O, Gézsi A, Semsei AF, Antal P, Erdélyi DJ, Schermann G, Kutszegi N, Csordás K, Hegyi M, Kovács G, et al: Candidate gene association study in pediatric acute lymphoblastic leukemia evaluated by Bayesian network based Bayesian multilevel analysis of relevance. BMC Med Genomics 5: 42, 2012.

102. Sakamoto KM, Grant S, Saleiro D, Crispino JD, Hijiya N, Giles F, Platanias L and Eklund EA: Targeting novel signaling pathways for resistant acute myeloid leukemia. Mol Genet Metab 114: 397-402, 2015

103. Bruserud $\varnothing$, Nepstad I, Hauge M, Hatfield KJ and Reikvam H: STAT3 as a possible therapeutic target in human malignancies: Lessons from acute myeloid leukemia. Expert Rev Hematol 8: $29-41,2015$

104. Munoz J, Dhillon N, Janku F, Watowich SS and Hong DS STAT3 inhibitors: Finding a home in lymphoma and leukemia. Oncologist 19: 536-544, 2014.

105. Hayakawa F, Sugimoto K, Harada Y, Hashimoto N, Ohi N, Kurahashi S and Naoe T: A novel STAT inhibitor,OPB-31121, has a significant antitumor effect on leukemia with STAT-addictive oncokinases. Blood Cancer J 3: e166, 2013.

106. Zhu Z, Lu X, Jiang L, Sun X, Zhou H, Jia Z, Zhang X and Ma L: STAT3 signaling pathway is involved in decitabine induced biological phenotype regulation of acute myeloid leukemia cells. Am J Transl Res 7: 1896-1907, 2015.

107. Selvi N, Kaymaz BT, Gündüz C, Aktan C, Kiper HD, Sahin F, Cömert M, Selvi AF, Kosova B and Saydam G: Bortezomib induces apoptosis by interacting with JAK/STAT pathway in K562 leukemic cells. Tumour Biol 35: 7861-7870, 2014.

108. Kiper HD, Tezcanli Kaymaz B, Gokbulut AA, Selvi N, Avci CB Kosova B, Iskender G, Yandim MK, Gunduz C, Sahin F, et al: STAT pathway in the regulation of zoledronic acidinduced apoptosis in chronic myeloid leukemia cells. Biomed Pharmacother 67: 527-532, 2013.

109. Zhao S, Guo J, Zhao Y, Fei C, Zheng Q, Li X and Chang C: Chidamide, a novel histone deacetylase inhibitor, inhibits the viability of MDS and AML cells by suppressing JAK2/STAT3 signaling. Am J Transl Res 8: 3169-3178, 2016.

110. Chan KT, Li K, Liu SL, Chu KH, Toh M and Xie WD: Cucurbitacin B inhibits STAT3 and the Raf/MEK/ERK pathway in leukemia cell line K562. Cancer Lett 289: 46-52, 2010.

111. Cai H, Qin X and Yang C: Dehydrocostus lactone suppresses proliferation of human chronic myeloid leukemia cells through Bcr/Abl-JAK/STAT signaling pathways. J Cell Biochem 118: 3381-3390, 2017.

112. Jung JH, Kwon TR, Jeong SJ, Kim EO, Sohn EJ, Yun M and Kim SH: Apoptosis induced by tanshinone IIA and cryptotanshinone is mediated by distinct JAK/STAT3/5 and SHP1/2 signaling in chronic myeloid leukemia K562 cells. Evid Based Complement Alternat Med 2013: 805639, 2013. 
113. Ma L, Zhu Z, Jiang L, Sun X, Lu X, Zhou M, Qian S and Jianyong L: Matrine suppresses cell growth of human chronic myeloid leukemia cells via its inhibition of the interleukin-6/Janus activated kinase/signal transducer and activator of transcription 3 signaling cohort. Leuk Lymphoma 56: 2923-2930, 2015.

114. Jia X, Yang W, Han J and Xiong H: Effects of lentivirus mediated STAT3 silencing on human chronic myeloid leukemia cells and leukemia mice. Int J Clin Exp Med 7: 4031-4037, 2014.

115. Stella S, Tirrò E, Conte E, Stagno F, Di Raimondo F, Manzella L and Vigneri P: Suppression of survivin induced by a BCR-ABL/JAK2/STAT3 pathway sensitizes imatinib-resistant CML cells to different cytotoxic drugs. Mol Cancer Ther 12: 1085-1098, 2013.

116. Allen JC, Talab F,Zuzel M, Lin K and Slupsky JR: c-Abl regulates Mcl-1 gene expression in chronic lymphocytic leukemia cells. Blood 117: 2414-2422, 2011.

117. Folgiero V, Goffredo BM, Filippini P, Masetti R, Bonanno G, Caruso R, Bertaina V, Mastronuzzi A, Gaspari S, Zecca M, et al: Indoleamine 2,3-dioxygenase 1 (IDO1) activity in leukemia blasts correlates with poor outcome in childhood acute myeloid leukemia. Oncotarget 5: 2052-2064, 2014.

118. Adamaki M, Tsotra M, Vlahopoulos S, Zampogiannis A, Papavassiliou AG and Moschovi M: STAT transcript levels in childhood acute lymphoblastic leukemia: STAT1 and STAT3 transcript correlations. Leuk Res 39: 1285-1291, 2015.
119. Zhong Y, Feng J, Chen B, Cheng L, Li Y, Qian J, Ding J, Gao F and Xia G: Signal transducer and activator of transcription 3 (STAT3) gene polymorphisms are associated with treatment outcomes in acute myeloid leukemia. Int J Lab Hematol 34: 383-389, 2012

120. Redell MS, Ruiz MJ, Gerbing RB, Alonzo TA, Lange BJ, Tweardy DJ and Meshinchi S; Children's Oncology Group: FACS analysis of Stat $3 / 5$ signaling reveals sensitivity to G-CSF and IL-6 as a significant prognostic factor in pediatric AML: A Children's Oncology Group report. Blood 121: 1083-1093, 2013.

121. Levidou G, Sachanas S, Pangalis GA, Kalpadakis C, Yiakoumis X, Moschogiannis M, Sepsa A, Lakiotaki E, Milionis V, Kyrtsonis MC, et al: Immunohistochemical analysis of IL-6, IL-8/CXCR2 axis, Tyr p-STAT-3, and SOCS-3 in lymph nodes from patients with chronic lymphocytic leukemia: Correlation between microvascular characteristics and prognostic significance. BioMed Res Int 2014: 251479, 2014.

122. Danis E, Yamauchi T, Echanique K, Zhang X, Haladyna JN, Riedel SS, Zhu N, Xie H, Orkin SH, Armstrong SA, et al: Ezh2 controls an early hematopoietic program and growth and survival signaling in early $\mathrm{T}$ cell precursor acute lymphoblastic leukemia. Cell Rep 14: 1953-1965, 2016. 